\title{
OC-105 ROUTINE DUODENAL BULB BIOPSY IN COELIAC DISEASE: TIME TO CHANGE CLINICAL PRACTICE?
}

doi:10.1136/gut.2011.239301.105

K E Evans, ${ }_{1}{ }^{*}$ S S Cross, ${ }^{2}$ G R Sahota, ${ }^{1}$ A D Hopper, ${ }^{1}$ M Hadjivassiliou, ${ }^{3}$ D S Sanders ${ }^{1}$ Department of Gastroenterology, Royal Hallamshire Hospital, Sheffield, UK: ${ }^{2}$ Academic Unit of Pathology, Sheffield University, Sheffield, UK; ${ }^{3}$ Department of Neurology, Royal Hallamshire Hospital, Sheffield, UK

Introduction Historically Brunner's glands were thought to interfere with interpretation of villous atrophy in the duodenal bulb. Recent reports suggest that the duodenal bulb may be the only site to demonstrate villous atrophy (VA) in coeliac disease (CD). There are few data on the prevalence of lesions in non-coeliac patients.

Methods We aimed to compare the histological findings in the duodenal bulb and distal duodenum of patients with CD against controls having gastroscopy with duodenal biopsy. Indications included positive coeliac serology, family history, diarrhoea, and iron deficiency anaemia. A total of 461 patients were prospectively recruited. Biopsies were graded using the Marsh criteria by a single pathologist blinded to the clinical information.

Results 461 patients, (300 female, 161 male) median age 50 years (range 16-89) were analysed. 24 patients had VA in the bulb only, 6 had VA in distal duodenum only $(p=0.001)$ (table 1$)$. 1 control patient with HIV enteropathy had VA at both sites. $\mathrm{CD}$ in remission showed greater histological variability than new diagnosis CD ( $p=0.0018)$ and controls $(p=0.0001)$

Conclusion Villous atrophy may be present only in the duodenal bulb. In this study 11/126 (9\%) of new diagnosis CD and

Table 1 OC-105 Histology and serology in new diagnosis coeliac disease, coeliac disease in remission, and controls

\begin{tabular}{|c|c|c|c|c|c|c|c|}
\hline & $\mathbf{N}$ & $\begin{array}{c}\text { Coeliac } \\
\text { serology + ve }\end{array}$ & VA in D1 & VA in D2 & VA in D1 only & VA in D2 only & $\begin{array}{c}\text { Difference 1+ } \\
\text { Marsh Grade }\end{array}$ \\
\hline Controls & $250(54 \%)$ & 48 (19\%) & $1(0.0 \%)$ & $1(0.0 \%)$ & 0 & 0 & $18(7 \%)$ \\
\hline CD: new diagnosis & $126(27 \%)$ & $116(92 \%)$ & $115(91 \%)$ & $108(86 \%)$ & $11(9 \%)$ & $4(3 \%)$ & $21(17 \%)$ \\
\hline
\end{tabular}


$12 / 85(14 \%)$ of CD in remission demonstrated VA in the bulb alone. We recommend taking a biopsy from the bulb as well as the distal duodenum to diagnose suspected coeliac disease and reassess known cases.

Competing interests None.

Keywords coeliac disease, duodenal biopsy. 